\title{
Erratum: The impact of presbyopia on the quality of life in a semi-urban community in Southwest Nigeria
}

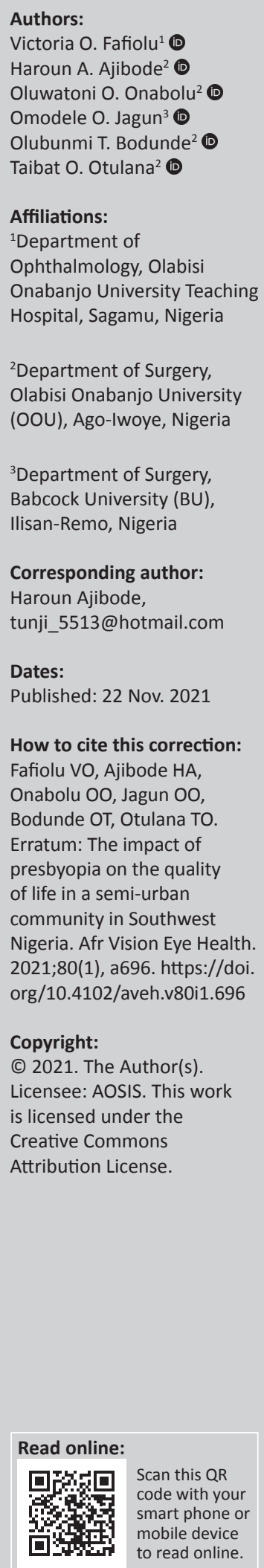

In the version of this article initially published, Fafiolu VO, Ajibod HA, Onabolu OO, Jagun KO, Bodunde OT, Otulana TO. The impact of presbyopia on the quality of life in a semi-urban community in Southwest Nigeria. Afr Vision Eye Health. 2020;79(1), a548. https://doi. org/10.4102/aveh.v79i1.548, the article section was given incorrectly. The correct section should be Original Research instead of Review Article.

The name of the second author was given incorrectly. The correct name should be Haroun A. Ajibode instead of Haroun A. Ajibod in the 'Authors' and 'How to cite this article' sections.

The initials of the fourth author were given incorrectly in the 'How to cite this article' section. The correct name should be Jagun OO instead of Jagun KO in the 'How to cite this article' section.

This correction does not alter the study's findings of significance or overall interpretation of the study's results. The publisher apologises for any inconvenience caused. 


\section{The impact of presbyopia on the quality of life in a semi-urban community in Southwest Nigeria}

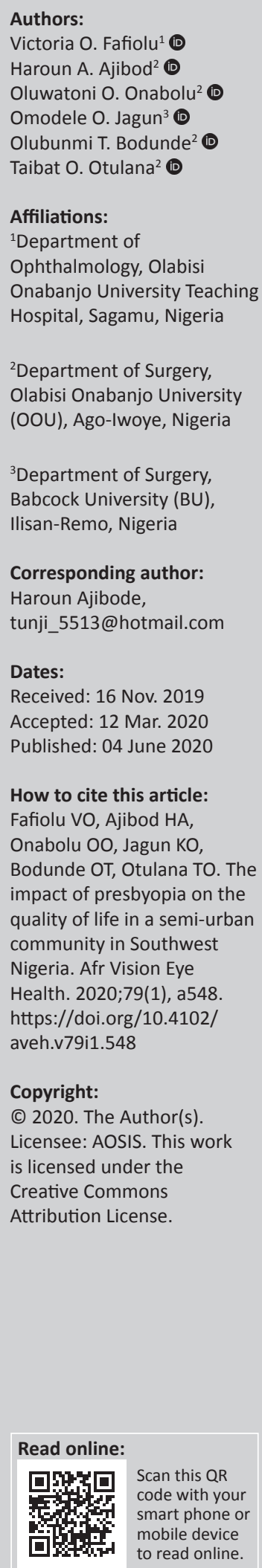

Background: Uncorrected presbyopia and its impact on the quality of life was performed as part of a community research towards strengthening the provision of optical services for Sagamu Local Government Area of Ogun State, Nigeria.

Aim: To determine the effect of uncorrected presbyopia on the quality of life of adults of 30 years old and above in Sagamu, Southwest, Nigeria.

Setting: This study consisted of the permanent resident adults of the town and village settlements within the local government.

Methods: Examination of respondents included distance visual acuity measurement with or without pinhole at 6 metres using the Snellen's chart. Near assessment was performed at 40 centimetres with the distance correction in place if required. The semi-structured questionnaire which contained demographics and near-vision task difficulties, et cetera, was administered. Ethical approval was obtained. The data were entered and analysed using Statistical Package for Social Sciences version 16 statistical software.

Results: The study showed that presbyopes significantly reported not being satisfied with near-vision ( $p=0.0001)$ and requiring help because of near-vision problems $(p=0.0004)$ more than non-presbyopes. The most difficult presbyopic activities were reading, writing, sorting grains, threading needle, cutting fingernails and recognising small objects. All were statistically significant (each with $p \leq 0.0001$ ).

Conclusion: The impact of reduced near vision on the quality of life in Sagamu, Nigeria, is striking and similar to findings around the world. So, any optical services plan for the local government area has to include presbyopic corrections.

Keywords: uncorrected presbyopia; near vision activities; quality of life; community-based; optical services; Sagamu; Nigeria.

\section{Introduction}

In low- and middle-income countries, studies have shown that more than half of adults over the age of 30 years have presbyopia, and the majority of these do not have corrective spectacles. ${ }^{1}$ The effects of uncorrected presbyopia include loss of employment opportunities, impaired quality of life for the individual and loss of economic gain for the family and society at large. Near visual impairment from uncorrected presbyopia is therefore of public health concern in many parts of the world. Its presence signifies inadequate eye care services because its treatment with corrective spectacles is most likely the simplest and most cost-effective eye care intervention.

Globally, few studies have been carried out to assess the impact of presbyopia on the quality of life of affected persons. The paucity of research on the prevalence of presbyopia and its impact on the quality of life in low- and middle-income countries is because of the perception that presbyopia is unimportant in locations where reading is uncommon. However, there is no evidence basis for this, and the few impact on the quality-of-life studies carried out so far had shown that presbyopia impacts greatly on the quality of life of people living in the rural areas of the developing countries as well., ${ }^{2,3}$ In addition, available studies used different lower age limits and definition for presbyopia, making comparison of findings difficult.

The Andhra Pradesh study ${ }^{4}$ in India found that subjects who are presbyopic and not using spectacles were more likely to report difficulty with near work than subjects who were using glasses. About $76.3 \%$ of the subjects stated they had moderate to severe difficulty in recognising small objects and performing near work such as threading a needle. ${ }^{4}$ 
In a study conducted amongst 1709 Tanzanian subjects found that compared with non-presbyopes, being presbyopic increased the odds of reporting some difficulty with nearvision tasks by twofolds, moderate difficulty by fivefolds and high difficulty by greater than eightfolds. Similarly, in a study conducted in the United States, it was discovered that presbyopia was associated with worse vision-targeted health-related quality of life compared to younger patients with emmetropia. ${ }^{5}$

Furthermore, in the Zanzibar study, ${ }^{6}$ it was found that $99.4 \%$ of participants required help for near activities at baseline, whilst at follow up 6 months after being provided presbyopic spectacles, $85.8 \%$ of participants no longer required help for near tasks. Also the mean visual score increased from $64.4 \%$ at baseline to $91.5 \%$. A study conducted in China by Lu et al. ${ }^{7}$ showed that persons with presbyopia have worse overall self-rated vision and high difficulty with activities of daily living such as threading a needle and sorting grains compared with non-presbyopes, whilst Luo et al. ${ }^{8}$ found that presbyopia is associated with a decrease in the quality of life similar to that seen in hypertension.

In Nigeria, Bekibele ${ }^{9}$ found that near-vision impairment had a significant impact on all domains of the quality of life, whilst Chiroma ${ }^{10}$ also found that presbyopia was associated with reduced quality of life. Similarly, in a more recent Calabar study, ${ }^{11}$ South-south Nigeria, presbyopic subjects in a community-based local council survey were significantly associated with reduced quality of life.

This study was designed to be part of a broad communitybased one for the determination of presbyopia and refractive errors in Sagamu Local Government Area (LGA) of Ogun State, Nigeria, towards planning a comprehensive optical services for the area and the environs. There was no previous data for the LGA. Part of this study had been reported in an earlier article. ${ }^{12}$

\section{Aim}

To determine the impact of uncorrected presbyopia on the quality of life of adults aged 30 years and above in Sagamu LGA of Ogun State, Nigeria.

\section{Research methods and design}

The study was carried out in Sagamu LGA of Ogun State in Nigeria amongst adults aged 30 years and above between 17 September 2012 and 25 November 2012.

Ogun State is one of the 36 States in Nigeria and situated between latitude $6.2^{\circ} \mathrm{N}$ and $7.8^{\circ} \mathrm{N}$ and longitude $3.0^{\circ} \mathrm{E}$ and $5.0^{\circ} \mathrm{E}$ in the south-west zone of the country. Eye care services are available at the eye clinic of the Olabisi Onabanjo University Teaching Hospital (OOUTH) in the area, some private hospitals and optical clinics. The eye clinic of OOUTH is the only public institution providing eye care service to the people of the local government.

\section{Study population}

Study population consisted of the permanent residents of the town and village settlements within the local government.

\section{Inclusion and exclusion criteria}

All individuals aged 30 years and above who had been resident in the study area for at least 6 months were enumerated and invited to participate in the study. The exclusion criteria were those with corrected visual acuity (VA) worse than 6/60, debilitated or severely ill persons and those whose VA could not be tested.

\section{Study design}

The study was a population-based descriptive and crosssectional study. It was conducted using a multi-stage stratified cluster random sampling technique with probability proportional to size. The sampling unit was the household which was taken to consist of all individuals who live under the same roof. The sampling details are contained in an earlier article on prevalence of presbyopia and spectacle coverage which was obtained at the same community-based dissertation research. ${ }^{12}$

The minimum sample size was calculated using the Leslie Kish formula. ${ }^{4}$ The minimum sample size calculated was 441 , but was adjusted to 662 after using 1.5 for design effects.

Each eligible individual was given an identification slip to bring to the examination centre where interviews, examinations and refractions were performed.

For the study, we used the N8 optotype (1M or 20/50 Snellen acuity) as the end point of near-vision testing. We measured near vision by placing the near chart $40 \mathrm{~cm}$ away from the subject. We defined people as presbyopic if both of the following were true: they were unable to read the N8 optotype with distance correction in place, or they were able to read at least one more line with the addition of a plus lens. The distance correction was determined with the aid of an autorefractor and subjective refraction using trial lenses. The degree of presbyopia was determined as the minimum amount of plus lens needed to achieve the maximum improvement in lines read to the end point (N8).

The semi-structured questionnaire which contained age, occupation, level of education, domiciliation, near-vision task difficulties, etc., was administered by the trained research assistants who were fluent in English and the local dialect. The questionnaire was translated from English to Yoruba and back-translated from Yoruba to English to ensure consistency. It was serially numbered to avoid duplication.

The data were entered and analysed using Statistical Package for Social Sciences V 16 statistical software. Near-vision tasks were then compared between those with uncorrected presbyopes and non-presbyopes. Also, their perception of quality of life for near tasks were compared. 


\section{Ethical considerations}

Ethical approval was obtained from the Ethical Committee of Olabisi Onabanjo University Teaching Hospital Research (Ethical Clearance Number: OOUTH/DA:326/795) on 14 September 2012. Consent was obtained from the Medical Officer of Health of Sagamu Local Government Council. Written and/or oral informed consent was obtained from the participants prior to the interview and examination. The tenets of the Declaration of Helsinki were strictly adhered to throughout the study.

\section{Results}

\section{Prevalence of presbyopia}

The overall prevalence of presbyopia (Table 1) amongst the study participants was $80.8 \%$ (95\% confidence interval [CI] 77.4-83.7). The youngest presbyope was 31 years old and 33 $(6.7 \%)$ of those with presbyopia were less than 40 years of age. There was an increasing prevalence with age $(p=0.0001)$ with a $100 \%$ prevalence in the $\geq 80$ years age group. However, there was a decline in prevalence in the 60-69 and 70-79 age groups compared to that of the 50-59 age group.

$X^{2}=122.6, p=0.0001$, degree of freedom $(\mathrm{df})=5 ; X^{2}=189.7$, $p=0.0001, d f=5$.

Table 2 shows that the prevalence of presbyopia is significantly associated with age, level of education and occupation. However, there is no significant association between prevalence of presbyopia and place of domicile or gender.

There is a sharp increase in the prevalence of presbyopia from $26 \%$ in the $30-39$ years age group to $93.8 \%$ in the $40-49$ age group. This is followed by a steady increase in 50-59 age group before a decline in the 60-69 and 70-79 age groups.

TABLE 1: Prevalence of presbyopia by gender and age group.

\begin{tabular}{lccc}
\hline $\begin{array}{l}\text { Age group } \\
\text { (years) }\end{array}$ & $n$ & $n$ & Frequency \\
\cline { 3 - 4 } Male & & & \\
$30-39$ & 38 & 8 & 21.1 \\
$40-49$ & 77 & 72 & 93.5 \\
$50-59$ & 63 & 62 & 98.4 \\
$60-69$ & 46 & 42 & 91.3 \\
$70-79$ & 12 & 11 & 91.7 \\
$\geq 80$ & 3 & 3 & 100.0 \\
Total & & 198 & 82.8 \\
Female & & & \\
$30-39$ & 89 & 25 & 28.1 \\
$40-49$ & 115 & 108 & 93.7 \\
$50-59$ & 86 & 85 & 98.8 \\
$60-69$ & 65 & 62 & 95.4 \\
$70-79$ & 12 & 11 & 91.7 \\
$\geq 80$ years & 2 & 2 & 100.0 \\
Total & & 293 & 79.4
\end{tabular}

Source: Ajibode HA, Fakolujo VO, Onabolu OO, Jagun OOA, Ogunlesi TO, Abiodun OA. A community-based prevalence of presbyopia and spectacle coverage in Southwest Nigeria. West Afr Coll Surg. 2016;6(4):66-82.

Note: Table 1 shows that the overall prevalence in men is higher than that in women although this is not statistically significant amongst the 608 (out of 662 enumerated participants) who completed the face-to-face assessment before the end of the survey in each locality.

Male age group: $N=239$; Female age group: $N=369$.
The prevalence of presbyopia is lowest in those with postsecondary school education $(66.1 \%)$, whilst it is highest in those without any formal education (90.7\%). With respect to occupation, the prevalence of presbyopia is highest amongst the unskilled labourers (95.2\%), whilst it is lowest amongst the professionals $(64.7 \%)$.

\section{Visual function and quality of life}

The study showed that presbyopes are significantly more likely to require help from others because of near-vision problems. This is highlighted in Table 3.

Table 3 shows that presbyopes are more likely to depend on other people than non-presbyopes.

Table 4 shows the proportion of study sample engaging in the near-vision activities and those having difficulty in carrying out the activity. The most difficult presbyopic activities were reading, threading needle and recognising small objects.

Table 5 shows that presbyopes were more likely to report moderate and severe difficulty in almost all the near-vision-

TABLE 2: Associations between presbyopia and socio-demographic factors in the 491 study participants who were presbyopic.

\begin{tabular}{|c|c|c|c|c|}
\hline \multirow[t]{2}{*}{ Characteristics } & \multirow[t]{2}{*}{$n$} & \multicolumn{2}{|c|}{ Presbyopia } & \multirow[t]{2}{*}{$p$} \\
\hline & & $N$ & $\%$ & \\
\hline \multicolumn{5}{|l|}{ Age in years } \\
\hline $30-39$ & 127 & 33 & 26.0 & 0.0001 \\
\hline $40-49$ & 192 & 180 & 93.8 & \\
\hline $50-59$ & 149 & 147 & 98.7 & \\
\hline $60-69$ & 111 & 104 & 93.7 & \\
\hline 70-79 & 24 & 22 & 91.7 & \\
\hline Above 80 & 5 & 5 & 100 & \\
\hline \multicolumn{5}{|l|}{ Level of education } \\
\hline No formal & 108 & 98 & 90.7 & 0.0001 \\
\hline Primary school completed & 178 & 153 & 86.0 & \\
\hline Secondary school completed & 145 & 123 & 84.8 & \\
\hline Post-secondary school level & 177 & 117 & 66.1 & \\
\hline \multicolumn{5}{|l|}{ Occupation } \\
\hline Professional & 153 & 99 & 64.7 & 0.0001 \\
\hline Non manual skilled labour & 53 & 43 & 81.1 & \\
\hline Manual skilled labour & 144 & 125 & 86.8 & \\
\hline Partially skilled labour & 198 & 170 & 85.9 & \\
\hline Unskilled labour & 21 & 20 & 95.2 & \\
\hline Unemployed & 39 & 34 & 87.2 & \\
\hline \multicolumn{5}{|l|}{ Domiciliation } \\
\hline Urban & 390 & 319 & 81.8 & 0.385 \\
\hline Rural & 218 & 172 & 78.9 & \\
\hline \multicolumn{5}{|l|}{ Gender } \\
\hline Males & 239 & 198 & 82.8 & 0.293 \\
\hline Females & 369 & 293 & 79.2 & \\
\hline
\end{tabular}

TABLE 3: Those requiring help from others because of near-vision problems.

\begin{tabular}{|c|c|c|c|c|c|c|}
\hline \multirow[t]{2}{*}{ Action required } & \multicolumn{2}{|c|}{ Presbyopia } & \multicolumn{2}{|c|}{ No presbyopia } & \multicolumn{2}{|c|}{ Total } \\
\hline & $n$ & $\%$ & $n$ & $\%$ & $n$ & $\%$ \\
\hline Require help & 109 & 18.0 & 9 & 1.0 & 118 & 19.0 \\
\hline No help required & 382 & 63.0 & 108 & 18.0 & 490 & 81.0 \\
\hline Total & 491 & 81.0 & 119 & 19.0 & 608 & 100 \\
\hline
\end{tabular}

$X^{2}=12.714 ; p=0.0002 ;$ odds ratio $=3.424$. 
TABLE 4: Those reporting engaging in and having difficulty with near-vision-related tasks.

\begin{tabular}{|c|c|c|c|c|c|c|c|c|}
\hline \multirow[t]{3}{*}{ Activity } & \multicolumn{4}{|c|}{ Engaging in activity } & \multicolumn{4}{|c|}{ Reporting difficulty with activity } \\
\hline & \multicolumn{2}{|c|}{ Male $(N=239)$} & \multicolumn{2}{|c|}{ Female $(N=369)$} & \multicolumn{2}{|c|}{ Male } & \multicolumn{2}{|c|}{ Female } \\
\hline & $n$ & $\%$ & $n$ & $\%$ & $n$ & $\%$ & $n$ & $\%$ \\
\hline Reading & 205 & 85.8 & 281 & 76.2 & 181 & 88.3 & 234 & 83.3 \\
\hline Writing & 198 & 82.8 & 278 & 75.3 & 119 & 60.1 & 163 & 58.6 \\
\hline Cooking & 57 & 23.8 & 273 & 74.0 & 6 & 10.5 & 77 & 28.2 \\
\hline Sorting grain & 79 & 33.1 & 325 & 88.1 & 34 & 43.0 & 170 & 52.3 \\
\hline Threading needles & 206 & 86.2 & 354 & 95.9 & 172 & 83.5 & 282 & 79.7 \\
\hline Cutting fingernails & 168 & 70.3 & 277 & 75.1 & 81 & 48.5 & 125 & 45.1 \\
\hline Dressing children & 52 & 21.8 & 250 & 67.8 & 2 & 3.8 & 43 & 17.2 \\
\hline Harvesting & 32 & 13.4 & 34 & 9.2 & 11 & 34.4 & 11 & 32.4 \\
\hline Identifying work tools & 99 & 41.4 & 104 & 28.2 & 38 & 38.4 & 37 & 35.6 \\
\hline Recognising small objects & 188 & 78.7 & 289 & 78.3 & 120 & 63.8 & 185 & 64.0 \\
\hline Lighting/adjusting lamp & 77 & 32.2 & 131 & 35.5 & 14 & 18.2 & 34 & 26.0 \\
\hline Winnowing grains & 25 & 10.5 & 48 & 13.0 & 2 & 8.0 & 10 & 20.8 \\
\hline
\end{tabular}

Note: $\%$ in column $3(4)=\frac{N \text { in column } 3(4)}{N \text { in column } 1(2)} \times 100$.

TABLE 5: Comparison of difficulty in near-vision tasks between presbyopes and non-presbyopes.

\begin{tabular}{|c|c|c|c|c|c|c|c|c|c|}
\hline \multirow[t]{3}{*}{ Tasks } & \multicolumn{9}{|c|}{ Levels of difficulty } \\
\hline & \multicolumn{2}{|c|}{ None } & \multicolumn{2}{|c|}{ Little } & \multicolumn{2}{|c|}{ Moderate } & \multicolumn{2}{|c|}{ Severe } & \multirow[t]{2}{*}{$p$} \\
\hline & $n$ & $\%$ & $n$ & $\%$ & $n$ & $\%$ & $n$ & $\%$ & \\
\hline \multicolumn{10}{|l|}{ Reading } \\
\hline Presbyopes (379) & 7 & 1.8 & 76 & 20.1 & 178 & 47.0 & 118 & 31.1 & 0.0001 \\
\hline Non-presbyopes (107) & 64 & 59.8 & 28 & 26.2 & 10 & 9.3 & 5 & 4.7 & \\
\hline \multicolumn{10}{|l|}{ Writing } \\
\hline Presbyopes (374) & 107 & 28.6 & 116 & 31.1 & 104 & 27.8 & 47 & 12.6 & 0.0001 \\
\hline Non-presbyopes (108) & 88 & 81.5 & 13 & 12.0 & 5 & 4.6 & 2 & 1.9 & \\
\hline \multicolumn{10}{|l|}{ Cooking } \\
\hline Presbyopes (248) & 171 & 69.0 & 41 & 16.5 & 20 & 8.0 & 16 & 6.5 & 0.001 \\
\hline Non-presbyopes (82) & 75 & 91.5 & 4 & 4.9 & 2 & 2.4 & 1 & 1.2 & \\
\hline \multicolumn{10}{|l|}{ Sorting grains } \\
\hline Presbyopes (314) & 122 & 38.9 & 85 & 27.1 & 63 & 20.1 & 44 & 10.9 & 0.0001 \\
\hline Non-presbyopes (90) & 78 & 86.7 & 8 & 8.9 & 4 & 4.4 & 0 & 0.0 & \\
\hline Presbyope (452) & 37 & 8.2 & 63 & 13.9 & 136 & 30.1 & 216 & 47.8 & 0.0001 \\
\hline Non-presbyopes (108) & 69 & 63.9 & 21 & 19.4 & 12 & 11.1 & 6 & 5.6 & \\
\hline \multicolumn{10}{|l|}{ Cutting fingernails } \\
\hline Presbyopes (343) & 150 & 43.7 & 106 & 30.9 & 46 & 13.4 & 41 & 12.0 & 0.0001 \\
\hline Non-presbyopes (102) & 8 & 87.3 & 10 & 9.7 & 2 & 2.0 & 1 & 1.0 & \\
\hline \multicolumn{10}{|l|}{ Dressing children } \\
\hline Presbyopes (229) & 185 & 80.8 & 18 & 7.9 & 17 & 7.4 & 9 & 3.0 & 0.003 \\
\hline Non-presbyopes (73) & 7 & 98.6 & 1 & 1.4 & 0 & 0.0 & 0 & 0.0 & \\
\hline \multicolumn{10}{|l|}{ Harvesting } \\
\hline Presbyopes (53) & 33 & 62.3 & 10 & 18.9 & 5 & 9.4 & 5 & 9.4 & 0.186 \\
\hline Non-presbyopes (13) & 11 & $84.6)$ & 0 & 0.0 & 2 & 15.4 & 0 & 0.0 & \\
\hline \multicolumn{10}{|l|}{ Identifying work tools } \\
\hline Presbyopes (153) & 85 & 55.6 & 17 & 11.1 & 32 & 20.9 & 19 & 12.4 & 0.001 \\
\hline Non-presbyopes (50) & 43 & 86.0 & 4 & 8.0 & 2 & 4.0 & 1 & 2.0 & \\
\hline Non-presbyopes (103) & 83 & 80.6 & 12 & 11.7 & 6 & 5.8 & 2 & 1.9 & \\
\hline \multicolumn{10}{|l|}{ Lighting/adjusting lamp } \\
\hline Presbyopes (152) & 109 & 71.7 & 21 & 13.8 & 15 & 9.9 & $7(4.6)$ & 4.6 & 0.031 \\
\hline Non-presbyopes (56) & 51 & 91.0 & 3 & 5.4 & 1 & 1.8 & $1(1.8)$ & 1.8 & \\
\hline \multicolumn{10}{|l|}{ Winnowing grains } \\
\hline Presbyopes (56) & 45 & 80.4 & 3 & 5.4 & 3 & 5.4 & $5(8.8)$ & 8.8 & 0.435 \\
\hline Non-presbyopes (17) & 16 & 94.1 & 1 & 5.9 & 0 & 0.0 & $0(0.0)$ & 0.0 & \\
\hline
\end{tabular}


TABLE 6: Satisfaction with near vision and general health between presbyopes and non-presbyopes.

\begin{tabular}{|c|c|c|c|c|c|c|c|c|c|}
\hline \multirow[t]{3}{*}{ Response of participants } & \multicolumn{4}{|c|}{ Presbyopes } & \multicolumn{4}{|c|}{ Non-presbyopes } & \multirow[t]{3}{*}{$p$} \\
\hline & \multicolumn{2}{|c|}{ Male } & \multicolumn{2}{|c|}{ Female } & \multicolumn{2}{|c|}{ Male } & \multicolumn{2}{|c|}{ Female } & \\
\hline & $n$ & $\%$ & $n$ & $\%$ & $n$ & $\%$ & $n$ & $\%$ & \\
\hline Not satisfied with near vision & 37 & 18.7 & 61 & 20.8 & 2 & 4.9 & 2 & 2.6 & $<0.001^{*}$ \\
\hline Not satisfied with general health & 2 & 1.0 & 18 & 6.1 & 0 & 0.0 & 1 & 1.3 & 0.087 \\
\hline Problem with family & 11 & 5.6 & 26 & 8.9 & 4 & 9.8 & 3 & 3.9 & 0.560 \\
\hline Having felt looked down upon & 14 & 7.1 & 27 & 9.2 & 4 & 9.8 & 2 & 2.6 & 0.240 \\
\hline Requiring help because of vision & 42 & 21.2 & 67 & 22.9 & 3 & 7.3 & 6 & 7.9 & $0.004^{*}$ \\
\hline
\end{tabular}

*, Significant $p$-value $<0.05$

related task except for activities like harvesting, lighting/ adjusting lamp and winnowing grains.

Table 6 shows that presbyopes are significantly more likely to complain about not being satisfied with near vision compared to non-presbyopes. Presbyopes are also more likely to report requiring help from others because of near-vision problems. However, there is no statistical difference between presbyopes and non-presbyopes in reporting problems with family, feeling looked down upon and being satisfied with general health.

\section{Discussion}

This study was carried out to determine a population-based impact of uncorrected presbyopia on the quality of life of adults aged 30 years and above in Sagamu LGA of Ogun state. This is important because although some populationbased studies on presbyopia have been carried out in Nigeria, ${ }^{10,11,12,13,14,15}$ many are not linked to quality of life, and there is none from this local government.

The overall prevalence of presbyopia (Table 1) amongst the study participants was $80.8 \%$ (95\% CI 77.4-83.7), with increasing prevalence with age $(p=0.0001)$ up to a $100 \%$ prevalence in the $\geq 80$ years age group. This is similar to the findings documented by other researchers in Nigeria and other parts of the world. $5,7,8,10,16$

There was no statistical difference between the prevalence of presbyopia between urban and rural dwellers (81.8\% [urban] vs. $78.9 \%$ [rural]). This is similar to the findings of Laviers ${ }^{6}$ in Zanzibar. However, Nirmalan et al. ${ }^{5}$ found a higher prevalence amongst rural dwellers, whilst Burke et al. ${ }^{16}$ found a higher prevalence amongst the town dwellers.

Multivariate analysis of the risk factors for presbyopia showed that older age (odds ratio $[\mathrm{OR}]=0.08, p=0.0001$ ) and lower level of education $(\mathrm{OR}=2.45, p=0.004)$ were associated with higher risk of presbyopia. However, there was no significant association between gender, occupation or place of domicile and a higher risk of presbyopia.

More details on prevalence of presbyopia is already published. ${ }^{12}$

The study showed that presbyopes are significantly more likely to require help from others because of near-vision problems as shown in Table 3.

\section{Impact on the quality of life}

With respect to the impact on the quality of life, this study found that $78.1 \%, 77.8 \%$ and $40.4 \%$ of presbyopes reported moderate to severe difficulty with reading, threading needles and writing, respectively. This is consistent with the findings of Chiroma ${ }^{10}$ in Abuja where $95.8 \%$ of presbyopes reported moderate to severe difficulty with reading and $75.6 \%$ reported moderate to severe difficulty with recognising small objects.

It is also similar to the findings of the Andhra Pradesh ${ }^{4}$ study where about $76.3 \%$ of subjects reported moderate to severe difficulty in recognising small objects and performing near work such as threading a needles.

There was an almost three-times dependency because of near-vision impairment in presbyopes compared to nonpresbyopes similar to findings previously documented by other researchers. $., 6,7,8$

Presbyopes significantly reported not being satisfied with near vision $(p=0.0001)$ and requiring help because of a nearvision problem $(p=0.0004)$ more than non-presbyopes. This is consistent with the findings previously documented in Tanzania ${ }^{3}$ and Abuja. ${ }^{10}$ It is also similar to that found in Ibadan $^{9}$ where it was documented that near-vision impairment had a significant impact on all domains of the quality of life.

Comparing difficulty in near-vision tasks between presbyopes and non-presbyopes as illustrated in Table 5, presbyopes had higher levels of difficulty for reading, writing, cooking, sorting grains, threading needle, cutting fingernails, dressing children, identifying working tools, recognising small objects, harvesting, lighting and adjusting lamp and winnowing grains. These differences were statistically significant in all except harvesting, lighting and adjusting lamp and winnowing grains. This is similar to findings in many studies around the world. ${ }^{8,9,10,11,16}$

Also, comparing satisfaction with near vision between presbyopes and non-presbyopes (Table 6), about 20\% of presbyopes were not satisfied, whilst less than $5 \%$ of nonpresbyopes felt so. This difference was statistically significant. Presbyopes are also more likely to report requiring help from others because of near-vision problems. However, there is no statistical difference between presbyopes and non-presbyopes 
in reporting problems with family, feeling looked down upon and being satisfied with general health.

In conclusion, the impact of reduced near vision on the quality of life in Sagamu, Ogun State, Nigeria (consisting of urban, semi-urban and rural communities) seems obvious and similar to findings in urban, ${ }^{4,5}$ semi-urban $^{4,10}$ and rural ${ }^{3,4,7}$ populations around the world. The study indicates a clear need for optical services to include presbyobic corrections in this community.

However, some limitations can be identified in this community-based study including the apparent dissimilarity between the presbyopes and non-presbyopes. The two groups are not age and sex-matched to reduce co-founders. The samples obtained from the community were just compared. This is common in all studies performed on this subject. So, a study to compare age and sex-matched groups is recommended for the future.

\section{Acknowledgements}

The contribution of Dr R.O. Musibau and Dr P.O. Abikoye, as well as that of Mrs M.C. Ogundipe during the data collection is appreciated. This work was originally part of the data obtained by one of the authors for the preparation and submission of her dissertation to the National Postgraduate Medical College of Nigeria for the award of a Fellowship in 2014.

\section{Competing interests}

The authors have declared that no competing interest exists.

\section{Authors' contributions}

V.O.F. made conceptual contributions and data collection, H.A.A. designed and drafted the manuscript, O.O.O. cowrote the manuscript and also collected data, O.O.J. collected data and reviewed the manuscript and O.T.B. and T.O.O. reviewed the manuscript and analysed the data.

\section{Funding information}

This research received no specific grant from any funding agency in the public, commercial or not-for-profit sectors.

\section{Data availability statement}

Data sharing is not applicable to this article.

\section{Disclaimer}

The views and opinions expressed in this article are those of the authors and do not necessarily reflect the official policy or position of any affiliated agency of the authors.

\section{References}

1. Patel I, West SK. Presbyopia: Prevalence, impact and intervention. Community Eye Health. 2007;20(63):40-41.

2. Patel $I$, Munoz $B$, Mkocha $A$, et al. Changes in function and spectacle use 2 months after providing presbyopic spectacle in rural Tanzania. Br J Ophthalmol. 2010;94(6):685-689. https://doi.org/10.1136/bjo.2008.145607

3. Patel I, Munoz B, Burke AG, et al. Impact of presbyopia on quality of life in a rural African setting. Ophthalmology. 2006;113(5):728-734. https://doi.org/10.1016/j. ophtha.2006.01.028

4. Nirmalan PK, Krishnaian S, Shamanna BR, Rao GN, Thomas R. A population based assessment of presbyopia in the state of Andhra Pradesh, South India: The Andhra Pradesh Eye Disease Study. Invest Ophthalmol Vis Sci. 2006;47(6):2324-2328. https://doi.org/10.1167/iovs.05-1192

5. Mcdonell PJ, Lee P, Spritzer K, Linelblad AS, Hays RD. Associations of presbyopia with vision targeted health related quality of life. Arch Ophthalmol. 2003;121(11):1577-1581. https://doi.org/10.1001/archopht.121.11.1577

6. Laviers HR, Omar F, Jecha H, Kassim G, Gilbert CE. Presbyopic spectacle coverage, willingness to pay for near correction and the impact of correcting uncorrected presbyopia in Zanzibar East Africa. Invest Ophthalmol Vis Sci. 2010;51(2):12341241. https://doi.org/10.1167/iovs.08-3154

7. Lu Q, Congdon N, He X, Murthy GV, Yang A, He W. Quality of life and near vision impairment due to functional presbyopia among rural Chinese adults. Inves Ophthalmol Vis Sci. 2011;52(7):4118-4123. https://doi.org/10.1167/iovs.10-6353

8. Luo BP, Brown GC, Luo SC, Brown MM. The quality of life associated with presbyopia. Am J Ophthalmol. 2008;145(4):618-622. https://doi.org/10.1016/j. ajo.2007.12.011

9. Bekibele $\mathrm{CO}$, Gureje O. Impact of self-reported visual impairment on quality of life in the Ibadan study of aging. Br J Ophthalmol. 2008;92(5):612. https://doi. org/10.1136/bjo.2007.124859

10. Chiroma MR, Jamda AM. Impact of uncorrected presbyopia on the quality of life in rural Gwagwalada, Nigeria. J Community Med Prim Health Care. 2017;29(1):6873.

11. Eni EN, Oku A, Duke RE. Presbyopia and vision-related quality of life in Calabar, Nigeria. Ophthalmol Res. 2019;10(3):1-11. https://doi.org/10.9734/or/2019/ v10i330105

12. Ajibode HA, Fakolujo VO, Onabolu OO, Jagun OOA, Ogunlesi TO, Abiodun OA. A community-based prevalence of presbyopia and spectacle coverage in Southwest Nigeria. J West Afr Coll Surg. 2016;6(4):66-82.

13. Umar MM, Nasiru M, Alhassan MB. Prevalence of presbyopia and spectacle correction coverage in a rural population of North West Nigeria. Clin Ophthalmol. 2015;9:1195-1201. https://doi.org/10.2147/OPTH.S81194

14. Uche JN, Ezegwui IR, Uche E, Onwasigwe EN, Umeh RE, Onwasigwe CN Prevalence of presbyopia in a rural African community. Rural Remote Health. 2014;14(3):2731.

15. Idowu OO, Aribaba OT, Onakoya AO, Rotimi-Samuel A, Musa KO, Akinsola FB. Presbyopia and near spectacle correction coverage among public school teachers in Ifo Township, South-West Nigeria. Niger Postgrad Med J. 2016;23(3):132-136. https://doi.org/10.4103/1117-1936.190342

16. Burke AG, Patel I, Munoz B, et al. Population based study of presbyopia in rural Tanzania. Ophthalmology. 2006;113(5):723-727. https://doi.org/10.1016/j. ophtha.2006.01.030 